\title{
BENIGN TUBERCULOUS INFILTRATION OF THE LUNG (EPITUBERGULOSIS)
}

\author{
BY
}

\author{
J. C. SPENCE, M.D., F.R.C.P.
}

(From the Babies' Hospital and Royal Victoria Infirmary, Newcastle-on-Tyne.)

The following observations may throw some light upon the condition described as epituberculous infiltration or epituberculosis, a condition which probably is not different from that formerly described as tuberculous splenopneumonia, Frühinfiltrat, or tuberculose inflammatoire.

It is difficult to define exactly the term epituberculous infiltration for it is used to denote a variable clinical picture, of which the underlying pathology is not known through lack of opportunity for post-mortem study. It was first used in 1920 by Eliasberg and Neuland to describe a benign clinical syndrome in a tuberculous child, of which the chief features were an extensive dense consolidation of the lung revealed by percussion, auscultation, and X-ray examination; a harsh cough without sputum; an absence of severe constitutional symptoms; an absence of an initial acute illness; a slow disappearance of the consolidation, without signs of softening or cavitation; a complete recovery without fibrosis or bronchiectasis. The nature of the lesion is considered by many to be an allergic reaction around a small primary tuberculous focus, but this has been deduced by speculation and not proved by pathological investigation. The argument that has been advanced in favour of this theory is that, were the whole lesion a caseous tuberculous process or gelatinous pneumonia, the illness would be more severe, the course of it less benign, and the result less satisfactory.

The three cases to be described had that combination of an extensive solid lesion of the lung, with relatively slight symptoms of illness, which justifies their being regarded as examples of children suffering from epituberculous infiltration of the lung. They were presumably tuberculous children, the skin tuberculin reaction being positive, and in two there was a definite history of contact. From none of them were tubercle bacilli recovered in the sputum or stomach washings. In the third a further investigation was pursued by exploring the lung lesion and examining the material obtained in the aperture of the explorirg needle. This was done twice at an interval of four weeks, and in two sites. On both occasions tubercle bacilli were present in the material. This placed the tuberculous nature of the process in this case beyond doubt and the evidence suggests that the whole lesion in so-called epituberculous infiltration is a caseous tuberculous process, yet producing no severe constitutional symptoms. 


\section{Case reports.}

The details of the three cases on which this communication is based are as follows :-

Case 1. A girl, R. G., 6 months old, came for the first time under observation on November 14th, 1927. She had not gained weight for two months and it was for this reason that advice was sought. For nearly three months the child had been coughing but there had been no other symptoms.

The father was a man of 21 who had been in poor health for a few years. On examination it was found that he had active pulmonary tuberculosis with tubercle bacilli in the sputum. The mother was healthy. There had been one other child, who had died a year earlier of tuberculous meningitis.

The child was pallid, thin, and weighing $10 \mathrm{lb}$. She was not ill. She looked contented and happy, and the face itself was fat. On examination there was a pronounced dullness of the right thorax from the apex to the third intercostal space in front, and to the mid-scapular level behind. The note was equally dull in the upper part of the axilla. Over this affected area the respiratory murmur was diminished to a degree suggesting a pleural effusion. Distant tubular breathing could be heard, but there were no râles or rhonchi. At the base of the lung the percussion note and air entry were normal. The signs over the left lung were normal.

The abdomen was not protuberant: liver and spleen not enlarged. The urine was free from cells, albumin and sugar. The heart was normal and not displaced. The skin, glands, mouth and naso-pharynx were normal. Hæmoglobin $=65$ per cent. Rectal temperature normal. Skin tuberculin reaction to $-1 \mathrm{c.cm}$. of a 1 in 1000 dilution was strongly positive, the reaction lasting ten days.

The existence of a localized empyema was considered possible, so an exploring needle was put into the second interspace in front and behind. No pus or fluid was found. A small amount of caseous material was present in the aperture of the needle's point, but this was not examined microscopically.

The child was kept in hospital for 10 months and remained happy and contented without symptoms of illness. For the first three weeks the temperature was normal. Then followed a bout of fever rising to $102^{\circ}$ for 10 days. There was no alteration in the signs in the lung during this fever. Apart from this the child was afebrile throughout her stay, except for two or three rises of temperature for single days which were attributed to ward infections. There was no gain in weight for the first three months. Thereafter there was a steady gain. At the age of 12 months the weight was $12 \mathrm{lb}$.; at 15 months $14 \frac{1}{2} \mathrm{lb}$; at 16 months $15 \frac{1}{2} \mathrm{lb}$.

The signs in the lung remained unaltered during her first three months in hospital. In February, 1928, (child then 9 months) the dullness of the percussion note over the right upper lobe began to diminish, and the respiratory murmur became more pronounced. This improvement continued. A slightly impaired percussion note could still be detected in September, 1928, (age 16 months) when the child was discharged, but the air entry to the upper lobe was normal.

The skin tuberculin reaction was repeated three times with $\cdot 1 \mathrm{c.cm}$. of a 1 in 10,000 dilution and on each occasion gave a positive reaction of several days duration.

On discharge the child was small and underweight, but was well covered with subcutaneous fat, and looked perfectly healthy. A year later at the age of 2 years, 4 months she was in good health, weighed $21 \frac{1}{2} \mathrm{lb}$., and was without cough. There was no splenomegaly, and no signs of disease could be elicited by auscultation or percussion.

In May, 1930, at the age of 3 she was a healthy looking child of $26 \mathrm{lb}$. without sign or symptom of disease. In November, 1931, at the age of $4 \frac{1}{2}$ years she was again in good health, and appeared to be completely cured.

A series of X-ray examinations was made and Figures 1, 2 and 3 are chosen from these to illustrate the X-ray appearance of the lesion, and the mannner and rate of its disappearance. After admission the size and density of the shadow remained 


\section{BENIGN TUBERCULOUS INFILTRATION OF THE LUNG}

unaltered for about 4 months. Fig. 1 (February 2nd, 1928) shows it at this stage. Fig. 2 shows the shadow as it was on August 11th, 1928, 9 months after admission; Fig. 3 on September 4th, 1929, a year after discharge. A later picture taken in June, 1931, shows that the shadow has completely disappeared. The consolidation lasted for about 2 years. When disappearing it receded first from the periphery of the lung.

Case 2. E. T., girl, aged 5 years admitted to hospital on March 5th, 1930. She first attended as an out-patient with the complaint of lassitude and pallor. She had had no recent acute illnesses.

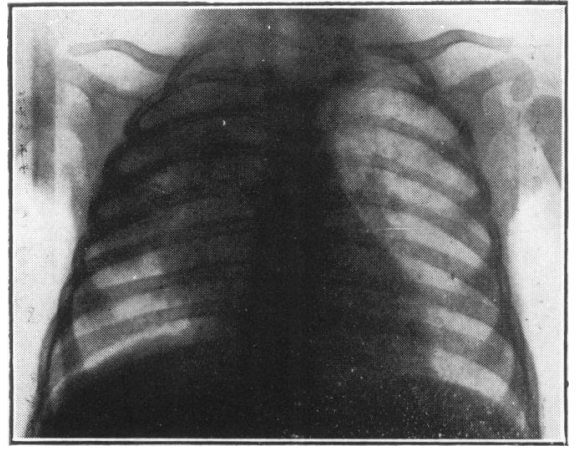

Fig. 1. Case 1. (Feb. 2, 1928). Skiagram taken 3 months after admission, showing the lung shadow as it persisted for the first four months.

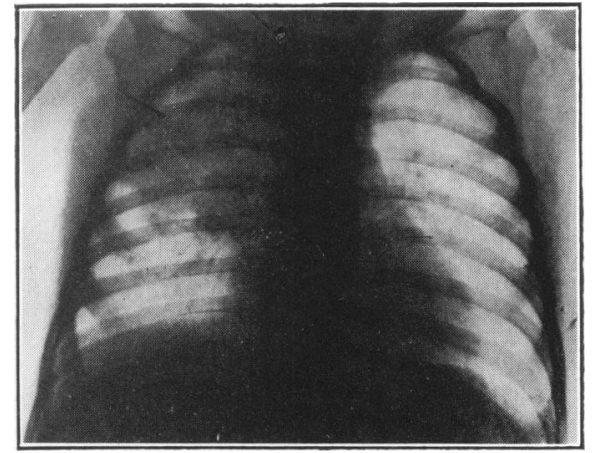

Fic. 2. Case 1. (Aug. 11, 1928). Skiagram taken 6 months later.

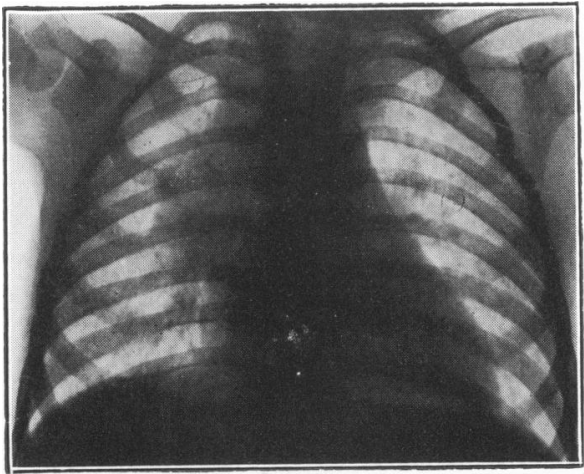

FIri. 3. Case 1. (Sept. 4, 1929). Skiagram taken a year after discharge from hospital.

In the family there was no definite evidence of tuberculous infection, but younger child aged $1 \frac{1}{2}$ years had died some time before of meningitis believed to have been tuberculous.

The child was small but fairly well nourished. Weight $28 \frac{1}{2} \mathrm{lb}$. She had no apparent symptoms and co-operated cheerfully and readily in the examination. She looked so healthy that it was suprising to find signs of a dull area over the whole of the upper part of the right lung. This was evident both in front and behind, and the signs of dullness with suppression of breath sounds suggested a localized pleural exudate. The area was explored by a needle and no fluid or pus obtained. The skin tuberculin reaction was strongly positive. X-ray examination revealed a dense area 
corresponding to almost the whole of the upper lobe with the lower limit sharply defined in its outer part (see Fig. 4).

From March, 1930, until January, 1932, she was kept under constant observation as an in-patient of the hospital, an later of Stannington sanatorium under the care of Dr. T. C. Hunter. During this time she continued in good health. There was no fever whatsoever: no cough and no sputum. She gained weight and at the age of 7 she weighed $41 \mathrm{lb}$.

The consolidation of the right upper lobe began to disappear about three months after coming under observation. The rate of disappearance was slow, signs of dullness

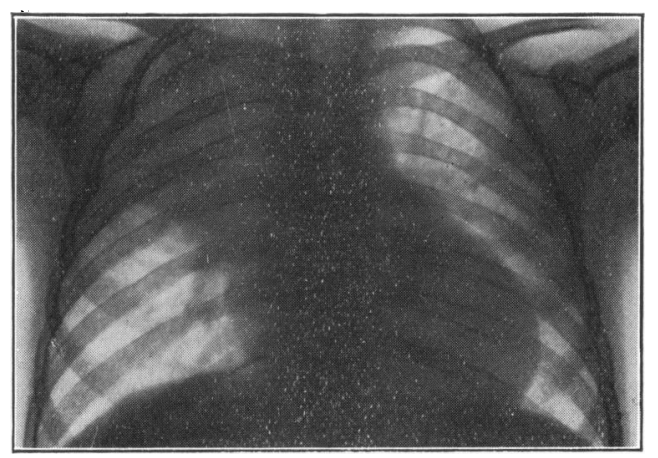

Fic. 4. Case 2. (March 17, 1930). Skiagram taken shortly after admission.

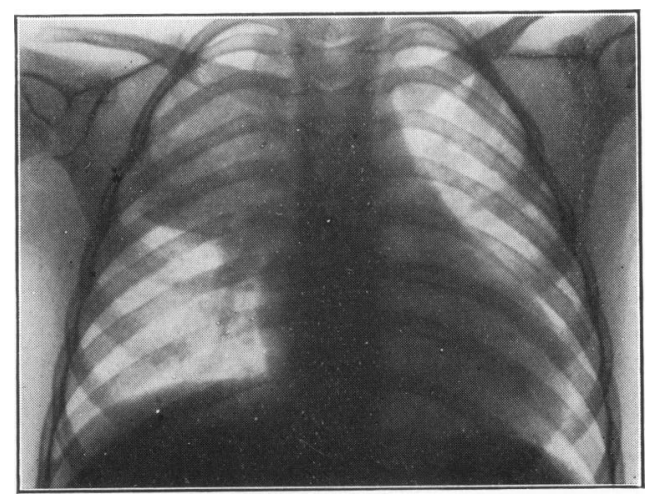

FI(i. 5. Case 2. (July 23, 1930). Skiagram 4 months later.

being still evident for more than a year. At no time was there any softening of the focus or evidence of cavitation. By January, 1932, all signs had disappeared and she looked in perfect health.

A series of $X$-ray examinations showed a slow diminution in the size of the shadow receding from the outer margin of the lung (see Figures 4, 5, 6, 7). The last of these (Fig. 7) taken on October 30th, 1931, shows only an increased hilum shadow on the right side compared with that on the left.

The signs and X-ray appearances of consolidation in the lung were in this child very similar to those in the first case, but disappeared more slowly. 
Case 3. A boy, W. S., aged 7 months, admitted to hospital on July 3rd, 1931 . Brought for advice because of dyspepsia and failure to gain weight.

The mother died of pulmonary tuberculosis 9 weeks before the chitd was admitted. She had been in daily contact with him for the first three months of his life, and during this time she had had fever, with abundant sputum, containing tubercle bacilli. The father was apparently healthy. There were four other living children aged 14, 13, 11 and 6 years. A child aged 2 died at about the time of the birth of this child. The cause of death was unknown.

The child was small and underweight, $9 \frac{1}{2} \mathrm{lb}$. He was lively and contented. The abdomen was protuberant, but not distended. His appearance suggested a condition of dyspepsia due to lack of care and proper feeding.

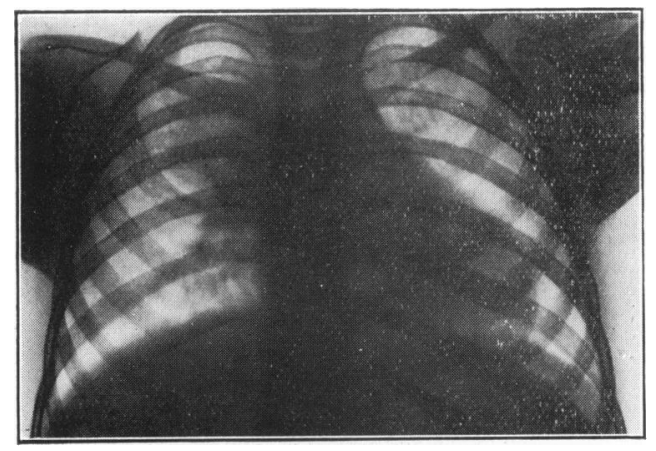

Frg. 6. Case 2. (Oct. 27, 1930`. Skiagram.

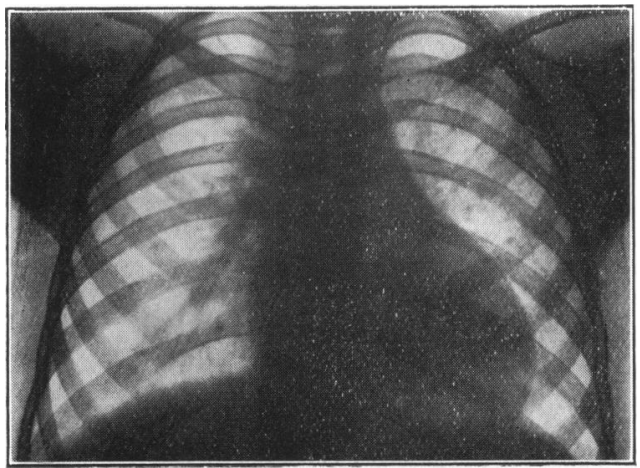

Fig. 7. Case 2. (Oct. 30, 1931). Skiugram 18 months after FI(i. 4.

On examination pronounced dullness was found over the upper part of the left lung. This was very evident in front and in the axilla, and less pronounced behind. The area of dullness extended down to the nipple. The breath sounds were diminished in that area and there was complete absence of crepitations and râles. On listening to the forced respiration provoked after crying slight wheezing rhonchi could be heard distantly, otherwise there were no adventitious sounds.

The right lung was normal. The heart was not displaced. The spleen was enlarged two fingers breadth before the costal margin. Liver not enlarged. The skin was moist and clear. Glands palpable on both sides of the neck down the sterno-mastoids. Mouth and throat clean. 
The temperature was normal. The urine contained a faint trace of albumin but no cells.

Skin tuberculin reaction was strongly positive to $1 \mathrm{c.cm}$. of 1 in 1,000 dilution. Hæmoglobin 60 per cent. Leucocytes $=11,600$.

The X-ray examination (Dr. Whately Davidson) on July 8th, 1931, showed a dense shadow of the upper and middle part of the left lobe (Fig. 8). The shadow diminished in intensity at the apex, and the base was clear. The diaphragm moved normally.

A diagnosis of tuberculous infiltraton of the lung was made. For the next two months there was a rapid improvement in his general condition but the signs in the chest were unaltered. A note made on September 4th, 1931, reads 'The signs and symptoms are those of a so-called epituberculosis. He has been in hospital 2 months and gained $3 \mathrm{lb}$. Still underweight, but quite happy and symptomless. He feeds well, smiles and is contented. Temperature usually below $99^{\circ}$, and occasionally reaches $100^{\circ}$, but no bouts of fever. There is no cough, but Sister has noted periods of slight wheeziness lasting an hour or two. In spite of the absence of symptoms a big massive lesion persists in the upper part of the left lung, unaltered since admission.'

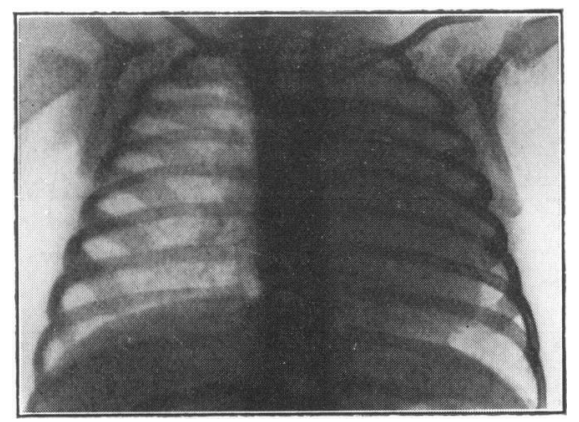

F'sc. \&. Case 3. (July 8, 1931). Skiagram taken shortly afier admission, aged 7 months.

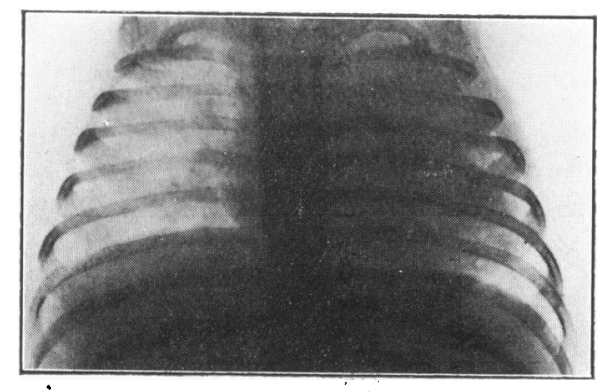

Futi. 9. ('ase 3. (Oct. 19, 1931). Skiagram taken 3 months later: patient afebrile and gaining weight.

On September 7 th the chest was explored. A needle was inserted into the third interspace in the mid-axillary line. No pus or fluid was obtained. A small amount of caseous material obtained in the needle was collected for examination. Two slide preparations were made. Each contained tubercle bacilli. A guinea pig was inoculated with the material. Killed $\mathbf{5}$ weeks later it showed typical tuberculous lesions from which the bacilli were again recovered. 


\section{BENIGN TUBERCULOUS INFILTRATION OF THE LUNG 7}

Four weeks later, on October 9th, 1931, a second exploration was performed. The needle was introduced in front in the mid-clavicular line in the third interspace and directed medially, so that the point of contact with the lung should be as far removed as possible from the site of the previous puncture. No pus or fluid was obtained. A small amount of necrotic material was again found in the needle. This was examined in two slide preparations and again tubercle bacilli were present.

The child has remained in hospital and has now been under observation for 6 months. The present weight (January $6 \mathrm{th}, 1932)$ is $13 \mathrm{lb} .2 \mathrm{oz}$. During the past six weeks the weight has been stationary. Splenomegaly persists. The general general condition improves. In November and December (5th and 6th months of sojourn in hospital) the glands in the neck increased in size but these are now subsiding.

A second X-ray examination (Fig. 9) on October 19th, 1931, shows the dense shadow persisting, but diminishing in size, receding from the periphery. A third $\mathrm{X}$-ray on January 6th, 1932, shows no further change.

\section{Discussion.}

The chief point of interest in these three cases is that clinically they resembled each other in being tuberculous children, each with a massive lesion of the lung which was benign in character and lasted for a year or more, without much disturbance of the general health beyond some pallor and loss of weight in the early stages.

In the first two the evidence that the lesion was tuberculous was only presumptive. In favour of this view there are the facts that both had positive skin tuberculin reactions, and one a history of contact with a tuberculous parent. Any other explanation of the nature of the consolidation is difficult. The children had not had pneumonia, and the complete disappearance of the lesion after it had been present for a year, and the recovery of the lung without signs of fibrosis or bronchiectasis, exclude bronchial obstruction as the cause.

Görter and Lignac have published a paper under the title ' Collateral inflammation of the lung round a tuberculous centre' in which they report the case of a girl of 3 years with a dense shadow in the right lung from which they recovered tubercle bacilli by lung puncture. They were able to obtain a post-mortem examination 18 months later, by which time the dense lesion had greatly decreased in size. They put forward the view that the most probable explanation of the process was that from a small caseous focus there spread a collateral inflammation over the largest part of the affected lobe, and that an acute infection with pneumococci played an important role in this process. But in the present cases there was nothing to suggest or prove a recent pneumococcal infection.

The third case recorded above was infected at a very early age, shortly after birth, so the failure to gain weight in the first six months of his life had had a more evident effect on his general condition. Otherwise the physical signs of the lesion and his progress resembled those in the first two cases. In this third case the tuberculous nature of the process has been proved beyond doubt by recovery of tubercle bacilli directly from the lung at two sites and on two occasions. The first exploration was made at a point which 
might conceivably have been the primary tuberculous focus, small in size and central in site. The second exploration was made at a point near the periphery of the consolidated area, as far as possible from the point of the first exploration. Tubercle bacilli were obtained in equal number and with equal facility from both parts of the lesion. It is clear, therefore, that in this case we have an infant infected shortly after birth with a large tuberculous lesion affecting almost the whole of the upper half of the lung, yet causing comparatively little disturbance to his health and no fever, and permitting a gain of weight.

\section{Conclusions.}

This communication draws attention to the value of careful examination of material obtained in the syringe needle when exploring the chests of cases of this type.

Of the cases which are described the chief point of clinical importance is that they demonstrate that even a young infant has a great power of recovery from tuberculous lesions of the lung, a view which Armand-Delille and others" have maintained for some years.

\section{REFERENGES.}

1. Eliasberg, H., \& Neuland, W., Jahrb. f. Kinderh., Berlin, 1920, XCIII, 88.

2. Görter, E., \& Lignac, G. O. E., Acta Pædiat., Stockholm, 1930, X, 87.

3. Armand-Delille, Vibert, J., \& Pannier, P., Rev. franc., de Pédiat., Paris, 1927, III, 1 . 